\title{
Early bile duct cancer
}

\author{
Jae Myung Cha, Myung-Hwan Kim, Se Jin Jang
}

\begin{abstract}
Jae Myung Cha, Department of Internal Medicine, University of Kyunghee College of Medicine, East-West Neo Medical Center, Seoul, Korea

Myung-Hwan Kim, Department of Internal Medicine, University of Ulsan College of Medicine, Asan Medical Center, Seoul, Korea Se Jin Jang, Department of Pathology, University of Ulsan College of Medicine, Asan Medical Center, Seoul, Korea

Correspondence to: Myung-Hwan Kim, MD, PhD, Department of Internal Medicine, Asan Medical Center, University of Ulsan College of Medicine, 388-1 Pungnap-dong, Songpa-gu, Seoul 138-736, Korea.mhkim@amc.seoul.kr

Telephone: +82-2-30103180 Fax: +82-2-4760824

Received: 2007-03-16 Accepted: 2007-04-10
\end{abstract}

\begin{abstract}
Bile duct cancers are frequently diagnosed as advanced diseases. Over half of patients with advanced bile duct cancer present with unresectable malignancies and their prognosis has been very poor even after curative resections. Although there has been a need to diagnose bile duct cancer at its early stage, it has been a difficult goal to achieve due to our lack of knowledge regarding this disease entity. Early bile duct cancer may be defined as a carcinoma whose invasion is confined within the fibromuscular layer of the extrahepatic bile duct or intrahepatic large bile duct without distant metastasis irrespective of lymph node involvement. Approximately $3 \%-10 \%$ of resected bile duct cancers have been reported to be early cancers in the literature. The clinicopathological features of patients with early bile duct cancer differ from those of patients with advanced bile duct cancer, with more frequent asymptomatic presentation, characteristic histopathological findings, and excellent prognosis. This manuscript is organized to emphasize the need for convening an international consensus to develop the concept of early bile duct cancer.
\end{abstract}

(C) 2007 WJG. All rights reserved.

Key words: Early bile duct cancer; Prognosis; Histopathology

Cha JM, Kim MH, Jang SJ. Early bile duct cancer. World J Gastroenterol 2007; 13(25): 3409-3416

http://www.wjgnet.com/1007-9327/13/3409.asp

\section{INTRODUCTION}

Bile duct cancer is a malignancy arising from the epithelial cells of the bile duct. It occurs with a greater frequency in Asian countries and its incidence has steadily increased in the United States and Europe over the past three decades ${ }^{[1,2]}$. As surgery still remains the only curative treatment for this tumor and earlier detection is a prerequisite for a curative resection ${ }^{[1,3]}$, there has been a need to diagnose bile duct cancer at its early stage. Despite advances in the diagnostic modalities, it has been a difficult goal to achieve due to our lack of knowledge regarding this disease.

There has not been a review article focusing on early bile duct cancer in the English literature. Recently, we have suggested that early bile duct cancer might not be a very rare disease entity, and its clinicopathological features may differ from those of advanced bile duct cancers ${ }^{[4]}$. The present review focuses on the definition and characteristic features of early bile duct cancer based on original articles ${ }^{[4-11]}$ describing early bile duct cancer. We hope that this review article will assist in understanding the concept of early bile duct cancer and ultimately serve to identify more of such patients.

\section{ANATOMY OF THE BILE DUCT}

Bile ducts are anatomically classified as either intrahepatic or extrahepatic bile duct. Extrahepatic bile duct is classified as perihilar or distal bile duct ${ }^{[2,13]}$, and intrahepatic bile ducts are classified as either intrahepatic large or small bile ducts ${ }^{[14,15]}$. Intrahepatic large bile ducts roughly correspond to ducts from the first to the fourth branches of the right and left hepatic ducts. Intrahepatic small bile ducts are further classified as septal bile ducts, interlobular bile ducts, or bile ductules according to their size and location. Intrahepatic large bile ducts are grossly visible and characterized by the presence of a fibrous ductal wall, while intrahepatic small bile ducts are recognizable using only a microscope and except for the septal bile ducts, characterized by the absence of a fibrous ductal wall ${ }^{[1,15]}$.

Microscopically, the bile duct is lined by a single layer of columnar cells and its wall consists of intermixed dense fibrous tissue and muscle fibers, the fibromuscular layer (Figure 1$)^{[16,17]}$. Biliary epithelial cells lining extrahepatic bile duct and intrahepatic large bile ducts have a different embryologic origin and phenotype from biliary epithelial cells lining intrahepatic small bile ducts ${ }^{[18]}$. Defining the layer of bile duct wall is often not easy in intrahepatic large bile ducts and impossible in intrahepatic small bile ducts, as the fibromuscular layer is very scant or absent ${ }^{[16,17]}$. Therefore, it is difficult to apply the concept of early cancer, which requires the histologic determination of the extent of bile duct wall invasion, to cholangiocarcinomas 

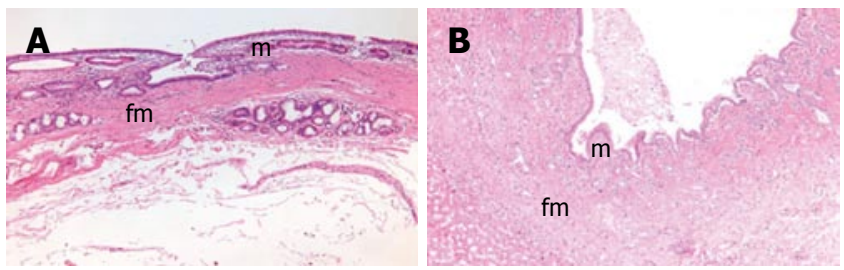

Figure 1 Normal histological layer of bile duct wall. A: Normal extrahepatic bile duct; $\mathbf{B}$ : Normal intrahepatic bile duct. Bile duct is lined by a single layer of columnar cells and its wall has a fibromuscular layer $(\mathrm{HE}, \times 100)$. m: mucosa layer, fm: fibromuscular layer.

\begin{tabular}{|c|c|c|c|c|c|}
\hline \multirow[t]{2}{*}{ Author } & \multirow[t]{2}{*}{ Yr } & \multicolumn{2}{|c|}{ Depth of invasion } & \multirow{2}{*}{$\begin{array}{l}\text { Number } \\
\text { of early } \\
\text { cancer }\end{array}$} & \multirow{2}{*}{$\begin{array}{l}\text { Total number of } \\
\text { cholangiocarcinoma }\end{array}$} \\
\hline & & Mucosa & Fibromuscular & & \\
\hline Tsunoda et al ${ }^{[5]}$ & 1989 & 3 & 5 & $8(6 \%)$ & 146 \\
\hline Yamaguchi $^{[6]}$ & 1992 & & $\mathrm{NC}$ & 7 & NM \\
\hline Mizumoto et $a l^{[7]}$ & 1993 & 4 & 10 & $14(8 \%)$ & 171 \\
\hline Bhuiya et al ${ }^{[8]}$ & 1993 & & $\mathrm{NC}$ & $7(10 \%)$ & 70 \\
\hline Kurosaki et al ${ }^{[9]}$ & 1998 & & $\mathrm{NC}$ & $7(8 \%)$ & 90 \\
\hline Tamada et al ${ }^{[10]}$ & 2001 & & $\mathrm{NC}$ & $10(18 \%)$ & 55 \\
\hline Lim et al ${ }^{[11]}$ & 2006 & 11 & 10 & $23(3 \%)^{1}$ & 742 \\
\hline Cha et $a l^{[4]}$ & 2006 & 16 & 45 & $61(10 \%)$ & 614 \\
\hline
\end{tabular}

NC: not classified; NM: not mentioned. ${ }^{1}$ Two cases were not included in the evaluation of depth of invasion.

originating from intrahepatic small bile ducts.

\section{DEFINITION}

The concept of early cancer in the hollow viscus has been already established, however, there have been no worldwide accepted criteria for early bile duct cancer. Sporadic cases of early bile duct cancer have been reported, and these articles mainly originated from Japan and South Korea (Table 1) ${ }^{[4-11]}$. Physicians from other countries may have overlooked cases of early bile duct cancer due to a lack of recognition and the rarity of this disease. The concept of early bile duct cancer was raised by the Japan Biliary Association in $1983^{[19]}$, and the used criteria were based on the depth of cancer invasion into the bile duct wall. Patients with cancer invasion confined within the fibromuscular layer of extrahepatic bile duct showed significantly better postoperative survival rates than patients with cancer invasion beyond the fibromuscular layer ${ }^{[5,7,8]}$.

Mizumoto et al ${ }^{[7]}$ reported a 5 years survival rate for patients with cancer invasion within the fibromuscular layer of $100 \%$. On the other hand, rates for patients with cancer invasion of the subserosa and serosa were $46 \%$ and $15 \%$, respectively. Tamada et $a l^{[10]}$ and Kurosaki et $a l^{[0]}$ proposed that extrahepatic pT1 bile duct cancer was associated with a better prognosis than advanced bile duct cancer. Kurosaki et al $l^{[0]}$ reported a 5 -year survival rate for 7 patients with pT1 bile duct cancer of $86 \%$. Based on these observations, bile duct cancer whose invasion is confined within the fibromuscular layer of extrahepatic bile duct was termed an early bile duct cancer (Table 2),
Table 2 Suggested definition for early bile duct cance

Bile duct cancer whose invasion is confined within the fibromuscular layer of the extrahepatic bile duct or intrahepatic large bile duct without distant metastasis irrespective of lymph node involvement

Table 3 Changes in T classification of the AJCC staging for extrahepatic bile duct cancer

\begin{tabular}{|c|c|c|c|}
\hline \multicolumn{2}{|c|}{ AJCC $5^{\text {th }}$ edition $^{[21]}$} & \multicolumn{2}{|c|}{ AJCC $6^{\text {th }}$ edition $^{[22]}$} \\
\hline pT & Tumor invasion & pT & Tumor invasion \\
\hline T1a & $\begin{array}{l}\text { Subepithelial connective } \\
\text { tissue }\end{array}$ & T1 & Confined to the bile duct \\
\hline $\mathrm{T} 1 \mathrm{~b}$ & Fibromuscular layer & $\mathrm{T} 2$ & Beyond the bile duct wall \\
\hline $\mathrm{T} 2$ & $\begin{array}{l}\text { Perifibromuscular } \\
\text { connective tissue }\end{array}$ & $\mathrm{T} 3$ & Liver, gallbladder, pancreas \\
\hline $\mathrm{T} 3$ & $\begin{array}{l}\text { Liver, pancreas, } \\
\text { gallbladder, stomach, } \\
\text { duodenum, colon }\end{array}$ & $\mathrm{T} 4$ & $\begin{array}{l}\text { Duodenum, colon, stomach, } \\
\text { abdominal wall }\end{array}$ \\
\hline
\end{tabular}

AJCC: American Joint Committee on Cancer.

while invasion beyond the fibromuscular layer was termed an advanced bile duct cancer. Main limitations of these studies are that they are based on retrospective studies with relatively small sample size.

On the other hand, there has been no attempt to define an intrahepatic early bile duct cancer in the literature, as it is difficult to apply the above criteria to intrahepatic bile duct cancer because they usually lack the fibromuscular layer in the bile duct wall. The histology of intrahepatic large bile duct, however, does not differ from that of extrahepatic bile duct in that they are grossly visible and have a fibromuscular layer in the wall ${ }^{[16]}$; therefore, we suggested that intrahepatic early bile duct cancer arising from intrahepatic large bile duct may be defined using the same criteria for extrahepatic early bile duct cancer ${ }^{[4]}$. The massforming cholangiocarcinoma arising from intrahepatic small bile duct, so called "peripheral cholangiocarcinoma", should be differentiated, as they differ clinicopathologically from bile duct cancers arising from extrahepatic bile duct or intrahepatic large bile duct ${ }^{4,200}$, and is excluded from the concept of early bile duct cancer. Internationally agreed definition for intrahepatic early bile duct cancer is needed in future studies.

\section{EARLY BILE DUCT CANCER VS T1 BILE DUCT CANCER}

As the previous T1 extrahepatic bile duct cancer was defined as "tumors invading subepithelial connective tissue and the fibromuscular layer" based on the $5^{\text {th }}$ edition of American Joint Committee on Cancer (AJCC) staging ${ }^{[21]}$, extrahepatic early bile duct cancers were classified as T1 extrahepatic bile duct cancers in some literature ${ }^{[0,10]}$. The $\mathrm{T}$ classification for extrahepatic bile duct cancer was refined in the new $6^{\text {th }}$ edition of the AJCC staging system (Table 3$)^{[22]}$. The previous T1a (tumors invading subepithelial connective tissue) and T1b (tumors invading the fibromuscular layer) classification in the AJCC $5^{\text {th }}$ 
Table 4 Changes in T classification of the AJCC staging for intrahepatic bile duct cancer

\begin{tabular}{|c|c|c|}
\hline pT & AJCC $5^{\text {th }}$ edition $^{[21]}$ & AJCC $6^{\text {th }}$ edition $^{[22]}$ \\
\hline $\mathrm{T} 1$ & $\begin{array}{l}\text { Solitary, } \leqslant 2 \mathrm{~cm} \text {, without } \\
\text { vascular invasion }\end{array}$ & $\begin{array}{l}\text { Solitary, without vascular } \\
\text { invasion }\end{array}$ \\
\hline $\mathrm{T} 2$ & $\begin{array}{l}\text { Solitary, } \leqslant 2 \mathrm{~cm} \text { with vascular } \\
\text { invasion or multiple, one lobe, } \\
\leqslant 2 \mathrm{~cm} \text { without vascular invasion }\end{array}$ & $\begin{array}{l}\text { Ssolitary, with vascular } \\
\text { invasion or multiple } \leqslant 5 \mathrm{~cm}\end{array}$ \\
\hline T3 & $\begin{array}{l}\text { Solitary, }>2 \mathrm{~cm} \text { with vascular } \\
\text { invasion or multiple, one lobe, } \\
\leqslant 2 \mathrm{~cm} \text {, with vascular invasion }\end{array}$ & $\begin{array}{l}\text { Multiple } \geqslant 5 \mathrm{~cm} \text { or major } \\
\text { portal/hepatic vein branch }\end{array}$ \\
\hline $\mathrm{T} 4$ & $\begin{array}{l}\text { Multiple, more than one lobe } \\
\text { or major portal/hepatic vein } \\
\text { branch }\end{array}$ & $\begin{array}{l}\text { Adjacent organ or perforation } \\
\text { of viscera }\end{array}$ \\
\hline
\end{tabular}

edition were merged into T1 (tumors confined to the bile duct histologically) in the AJCC $6^{\text {th }}$ edition. It may be difficult to discriminate extrahepatic early bile duct cancer from T1 extrahepatic bile duct cancer exactly in this new staging system, as the current T1 classification is defined using vague terms as "confined to the bile duct" without the mention about a precise histological layer such as a fibromuscular layer ${ }^{[23]}$. Although the AJCC $6^{\text {th }}$ edition describes T1 classification as "tumor confined to the bile duct", there is debate on how the bile duct is limited between pathologists also ${ }^{[17]}$. Therefore, it may be more distinct to define early bile duct cancer by a fibromuscular layer rather than a vague term, bile duct. On the other hand, intrahepatic bile duct cancer is staged similarly to hepatocellular carcinoma by different $\mathrm{T}$ classifications in AJCC staging system (Table 4) ${ }^{[22]}$. As intrahepatic early bile duct cancer arising from intrahepatic large bile ducts is defined by the depth of cancer invasion into the bile duct wall, it does not match with T1 intrahepatic bile duct cancer, which is based on vascular invasion and tumor size.

\section{PREVALENCE}

Although there is a significant geographic variation in the incidence of bile duct cancer, the worldwide incidence of bile duct cancer has risen over the past three decades ${ }^{[1,2]}$. Bile duct cancer is more prevalent in Asian countries than in the United States and Europe. For example, there is a high prevalence of intrahepatic bile duct cancer in areas such as Thailand (96/100000 in men and 38/100 000 in women $)^{[1]}$ and South Korea (75/100000 in men and $16 / 100000$ in women) ${ }^{[24]}$, whereas its prevalence in the United States is low with only $1-2 / 100000^{[25]}$. The geographic differences in the prevalence of bile duct cancer may be attributed to various distributions of local risk factors for bile duct cancer such as hepatolithiasis or liver-fluke infestation.

The exact prevalence of early bile duct cancer among bile duct cancer is unknown. Around 3\%-10\% of resected bile duct cancers was classified as early cancers in the literature (Table 1$)^{[4,5,7-11]}$. Over the past 8 years in our institution, of 614 patients with histologically confirmed primary bile duct cancer after resection, $61(10 \%)$ patients were found to have early bile duct cancers ${ }^{[4]}$. Eleven percent of intrahepatic bile duct cancers and $9 \%$ of total extrahepatic bile duct cancers were early bile duct
Table 5 Clinical characteristics of early bile duct cancer patients ${ }^{[4]}$

\begin{tabular}{|c|c|c|c|}
\hline Characteristics & Intrahepatic EBDC & Extrahepatic EBDC & Total \\
\hline Number of patients & 23 & 38 & 61 \\
\hline \multicolumn{4}{|l|}{ Demographic data } \\
\hline Age (yr) & $59 \pm 2$ & $60 \pm 2$ & $59 \pm 1$ \\
\hline $\begin{array}{l}\text { Gender } \\
\text { (male:female) }\end{array}$ & $13: 10$ & $31: 7$ & $44: 17$ \\
\hline \multicolumn{4}{|l|}{ Chief complaints } \\
\hline Asymptomatic & $14(23 \%)$ & $10(16 \%)$ & $24(39 \%)$ \\
\hline Jaundice & 0 & $10(16 \%)$ & $10(16 \%)$ \\
\hline Abdominal pain & $4(7 \%)$ & $5(8 \%)$ & $9(15 \%)$ \\
\hline Dyspepsia & $3(5 \%)$ & $3(5 \%)$ & $6(10 \%)$ \\
\hline Others & $2(3 \%)$ & $10(16 \%)$ & $12(19 \%)$ \\
\hline \multicolumn{4}{|l|}{ Associated disease } \\
\hline Hepatolithiasis & $9(15 \%)$ & $2(3 \%)$ & $11(18 \%)$ \\
\hline Clonorchiasis & $4(7 \%)$ & $4(7 \%)$ & $8(14 \%)$ \\
\hline $\begin{array}{l}\text { Biliary } \\
\text { papillomatosis }\end{array}$ & $10(16 \%)$ & $7(12 \%)$ & $17(28 \%)$ \\
\hline $\begin{array}{l}\text { Choledochal cyst } \pm \\
\text { AUPBD }\end{array}$ & $5(8 \%)$ & $6(10 \%)$ & $11(18 \%)$ \\
\hline
\end{tabular}

EBDC: early bile duct cancer; AUPBD: anomalous union of pancreaticobiliary ducts.

cancers, respectively. Our figure for extrahepatic early bile duct cancer is comparable to those of previous reports (Table 1$)^{[5-11]}$, however, it was the first report to describe the prevalence of intrahepatic early bile duct cancer ${ }^{[4]}$. The more frequent occurrence of early bile duct cancer in Japan and South Korea might be explained by two reasons: (1) known risk factors for bile duct cancer such as hepatolithiasis or liver-fluke infestation, are endemic in East Asia, and (2) higher chances to detect early bile duct cancers incidentally from more frequent performance of percutaneous transhepatic cholangioscopic examinations for other biliary diseases ${ }^{[26]}$. While an early bile duct cancer is not a common disease, it may not be a very rare entity either. Worldwide epidemiologic studies regarding the prevalence of early bile duct cancer is necessary, since articles on early bile duct cancer have originated mainly from the geographically adjacent Japan and South Korea $^{[4-11]}$.

\section{CLINICAL CHARACTERISTICS}

Little has been known about clinical characteristics and risk factors of early bile duct cancer. The peak age for early bile duct cancer patients is the seventh decade and the gender incidence shows a slight male preponderance ${ }^{[4-11]}$, which are not much different from those of advanced bile duct cancer patients ${ }^{[27]}$. Presenting symptoms of patients with early bile duct cancer are characteristic, in that they rarely complain of abdominal pain or jaundice typically associated with advanced bile duct cancer patients. Thirty nine percent of early bile duct cancer patients were asymptomatic and $84 \%$ of patients were non-jaundiced $\left(\right.$ Table 5) ${ }^{[4]}$.

Among known risk factors for bile duct cancer ${ }^{[1,2,25]}$, hepatolithiasis, liver-fluke infestation, biliary papillomatosis and choledochal cyst with or without anomalous union of pancreaticobiliary ducts are also associated with early bile duct cancers in our series ${ }^{[4]}$. Primary sclerosing cholangitis 


\begin{tabular}{|c|c|c|c|c|}
\hline & IG type & PI type & MF type & Total \\
\hline Cha et al ${ }^{[4]}$ & $35(57 \%)$ & $17(28 \%)$ & $1(2 \%)$ & $61^{1}$ \\
\hline Tsunoda et $a l^{[5]}$ & $7(88 \%)$ & $1(13 \%)$ & 0 & 8 \\
\hline Yamaguchi ${ }^{[6]}$ & $7(100 \%)$ & 0 & 0 & 7 \\
\hline Mizumoto et al ${ }^{[7]}$ & $10(71 \%)$ & $3(21 \%)$ & $1(7 \%)$ & 14 \\
\hline Tamada et al ${ }^{[10]}$ & $8(80 \%)$ & 0 & $2(20 \%)$ & 10 \\
\hline Lim $e t a l^{[11]}$ & $10(47 \%)$ & $1(5 \%)$ & $2(10 \%)$ & 21 \\
\hline Kozuka et al ${ }^{[36]}$ & $7(54 \%)$ & $5(39 \%)$ & $1(8 \%)$ & 13 \\
\hline
\end{tabular}

IG: intraductal-growing; PI: periductal-infiltrating; MF: mass-forming. ${ }^{1}$ Eight patients could not be classified into any types due to subtle gross changes.

is a risk factor more recognized in Western countries than in Asian countries ${ }^{[4,28-30]}$. Close association with biliary papillomatosis in patients with early bile duct cancer is interesting (Table 5) ${ }^{[4]}$, and it may also be explained by their prevalent endemic risk factors such as hepatolithiasis and liver fluke $\mathrm{e}^{[31]}$. Biliary papillomatosis has recently been shown to be a highly premalignant condition ${ }^{[31]}$, with which our findings are consistent. These chronic biliary diseases may lead to long-term irritation and inflammation of the bile duct epithelium with resultant fibrosis and dysplasia $^{[2,31]}$.

\section{LABORATORY DATA}

Most of early bile duct cancer patients showed a cholestatic profile on liver function tests ${ }^{[4]}$. Elevated levels of bile duct origin enzymes (serum alkaline phosphatase and gamma glutamyltransferase) are the most frequent abnormal biochemical results linked to early bile duct cancer patients, which are not different from the results associated with advanced bile duct cancer patients. In our series ${ }^{[25,27]}$, serum alkaline phosphatase and gamma glutamyl-transferase levels were elevated in $71 \%$ and $70 \%$ of early bile duct cancer patients, respectively ${ }^{[4]}$. In terms of tumor markers, serum carbohydrate antigen (CA) 19-9 screening has provided some assistance in the diagnosis of bile duct cancer $^{[25]}$. Its usefulness in the diagnosis of early bile duct cancer, however, is not so clear as CA 19-9 levels higher than $100 \mathrm{U} / \mathrm{mL}$ were noted in only $15 \%$ of early bile duct cancer patients ${ }^{[4]}$. Since increased serum levels of CA 19-9 less than $100 \mathrm{U} / \mathrm{mL}$ are not rare in benign conditions as well $^{[32,33]}$, measurement of serum CA 19-9 level may have a limited value in the diagnosis of early bile duct cancer.

\section{HISTOPATHOLOGY}

The Liver Cancer Study Group of Japan has recently proposed that bile duct cancers could be classified as one of three types based on gross morphology: mass-forming, periductal-infiltrating, or intraductal-growing types ${ }^{[34]}$. The periductal-infiltrating type was reported to be the most common gross type of extrahepatic bile duct cancer ${ }^{[1,35]}$, whereas the most common gross type of early bile duct cancer was intraductal-growing type, which was observed in $47 \%-100 \%$ of patients (Table 6$)^{[4-7,10,11,36]}$. Sometimes, it may be difficult to classify gross type of early bile duct cancers due to its subtle gross changes. Thirteen percent of patients with early bile duct cancer could not be classified
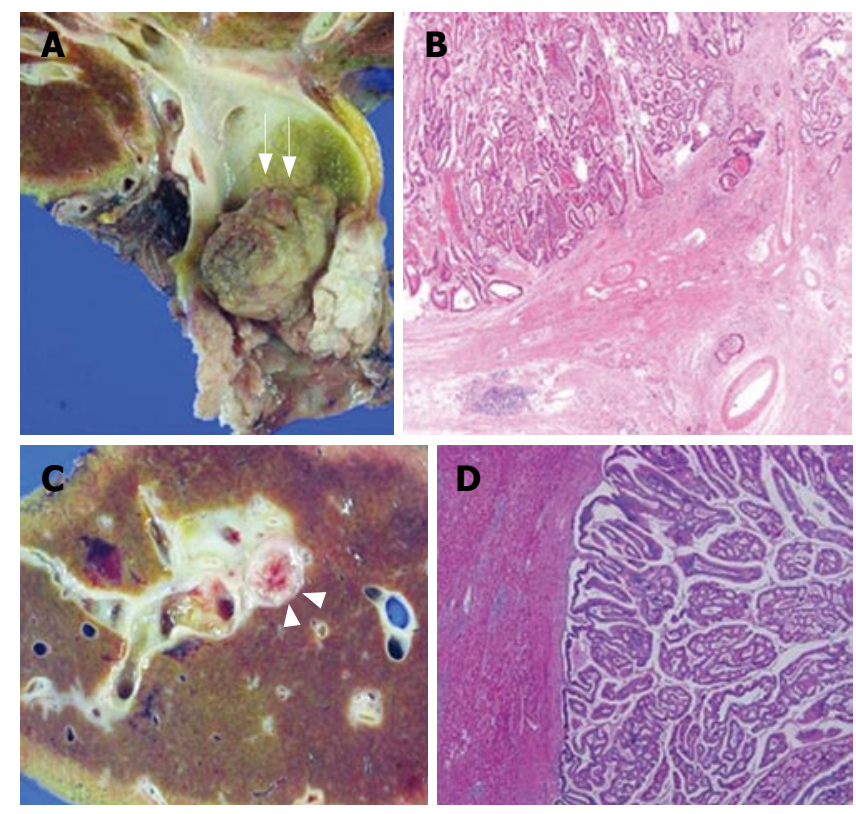

Figure 2 Macroscopic and microscopic findings of early bile duct cancers. A, B: Extrahepatic early bile duct cancer. A papillary mass (arrows) protruding into the common bile duct lumen is noted $(\mathbf{A})$. Although it is fairly large, its invasion is confined within the fibromuscular layer $(\mathrm{HE}, \times 100)(B) . C, D$ : An intrahepatic early bile duct cancer. Gross specimen of resected liver in patients with papillary mass (arrow heads) within the right intrahepatic bile duct. Tumor invasion is confined within the fibromuscular layer without hepatic parenchymal invasion $(H E, \times 10)$.

into any types in our series ${ }^{[4]}$. Some patients with early bile duct cancer showed large and fairly extensive tumors ${ }^{[4,11]}$, as these tumors mainly grew intraluminally and did not invade deeply into the fibromuscular layer (Figure 2).

Table 7 summarizes the microscopic findings and locoregional extensions in patients with early bile duct cancer. For histological classification, adenocarcinoma has been found to comprise greater than $90 \%$ of advanced bile duct cancers ${ }^{[2,23,37]}$, while it comprises only $10 \%-67 \%$ of early bile duct cancers ${ }^{[6,7,9,10,34]}$. On the other hand, papillary carcinoma was more common in early bile duct cancers, comprising up to $31 \%-90 \% 0^{[6,7,9,19,36]}$. Frequent occurrence of intraductal-growing type or papillary carcinoma in patients with early bile duct cancer may be explained by the fact that these tumor types grow and spread superficially along the bile duct mucosa and do not invade deeply into the bile duct wall ${ }^{[3]}$. Yamaguchi ${ }^{[6]}$ reported that none of 7 patients with early bile duct cancer showed venous or perineural invasions and lymph node metastasis. Mizumoto et al ${ }^{[7]}$ reported that $13(93 \%)$ of 14 patients with early bile duct cancer showed no locoregional extensions, and Kurosaki et $a l^{[9]}$ also found no locoregional extensions in $5(71 \%)$ of 7 patients with pT1 bile duct cancers. Lim et al ${ }^{[11]}$ showed portal hepatic lymph node metastasis in only one of 21 patients with early bile duct cancer, and we also showed no locoregional extensions in 53 (87\%) of 61 patients with early bile duct cancer ${ }^{[4]}$. The fact that postoperative locoregional extensions are limited in patients with early bile duct cancer also supports the concept of early bile duct cancer.

\section{DIAGNOSIS}

Comprehensive approaches using noninvasive and invasive 
Table 7 Microscopic classifications and locoregional extensions in early bile duct cancer

\begin{tabular}{|c|c|c|c|c|c|c|}
\hline & \multicolumn{3}{|c|}{ Microscopic classification } & \multicolumn{3}{|c|}{ Locoregional extensions } \\
\hline & Adenoca & Papillary ca & Others & LV (+) & PN (+) & $\operatorname{LN}(+)$ \\
\hline Cha et $a l^{[4]}(n=61)$ & $41(67 \%)$ & $19(31 \%)$ & $1(2 \%)$ & $4(7 \%)$ & $5(8 \%)$ & $1(2 \%)$ \\
\hline Yamaguchi $^{[6]}(n=7)$ & $3(43 \%)$ & $4(57 \%)$ & 0 & 0 & 0 & 0 \\
\hline Mizumoto et $a l^{[7]}(n=14)$ & $6(43 \%)$ & $8(57 \%)$ & 0 & $1(7 \%)$ & 0 & 0 \\
\hline Kurosaki et $a l^{[9]}(n=7)$ & & NM & & $2(29 \%)$ & 0 & 0 \\
\hline Tamada et $a l^{[10]}(n=10)$ & $1(10 \%)$ & $9(90 \%)$ & 0 & & NM & \\
\hline Limet $a l^{[11]}(n=21)$ & $6(29 \%)$ & $13(62 \%)$ & $2(10 \%)$ & 0 & 0 & $1(5 \%)$ \\
\hline Kozuka et al ${ }^{[36]}(n=13)$ & $3(23 \%)$ & $10(77 \%)$ & 0 & & NM & \\
\hline
\end{tabular}

Ca: carcinoma; LV (+): lymphovascular invasion; PN (+): perineural infiltration; LN (+): lymph node metastasis; NM: not mentioned.

modalities are needed for the diagnosis of early bile duct cancer. Masses, when small, may not be depicted using abdominal ultrasound (US) or computed tomography (CT) in patients with early bile duct cancer ${ }^{[11]}$. We failed to identify an evident mass using abdominal US in approximately half of early bile duct cancer patients $\mathrm{s}^{[4]}$. Although masses may not be revealed with conventional imaging studies, combination of elevated serum levels of bile duct origin enzymes and bile duct dilatation on imaging study warrants further evaluation. Elevated serum levels of bile duct origin enzymes was coupled with bile duct dilatation without visualization of a mass in $93 \%$ of early bile duct cancer patients in our experience ${ }^{[4]}$. The noninvasive nature of magnetic resonance cholangiography (MRC) may play a more important role in diagnosing early bile duct cancer patients because many of these patients are asymptomatic ${ }^{[4]}$. MRC can facilitate overviews of longitudinal cancer spread by assessing bile ducts upstream and downstream of the tumor simultaneously and permits assessment of the vessels ${ }^{[38,39]}$.

Radiographic findings alone may not distinguish reliably between malignant and benign lesions ${ }^{[40-42]}$. In addition, asymptomatic patients may be reluctant to undergo major operations without the certainty of a malignancy. If the suspected lesion is extrahepatic in location, histopathologic sampling is possible without difficulty by brush cytology and/or biopsy through endoscopic retrograde cholangiopancreatography (ERCP). Transpapillary peroral cholangioscopy can also be attempted, if available; however its value in identifying early bile duct cancer has not been addressed. Peroral cholangioscopy is more difficult for bile duct lesions above the hilum, because it has a limitation in the retroflexion capability of the scope tip ${ }^{[3]}$. Endoscopic ultrasound (EUS) appears to be an emerging technique to evaluate asymptomatic dilatation of extraheptic bile duct $^{[4]}$, and EUS-guided fine needle aspiration and biopsy has a greater sensitivity for detecting a malignancy than ERCP with brush cytology in cases with extrahepatic bile duct wall thickening ${ }^{[45]}$. The percutaneous transhepatic cholangioscopy (PTCS) is useful for intrahepatic bile duct lesions in histological diagnosis. Cholangioscopic findings in patients with early bile duct cancer vary from subtle mucosal changes to evident papillary masses of the bile duct $^{[4]}$, and identification of these changes allows targeted biopsy for an accurate diagnosis.

New molecular and imaging diagnostic modalities have emerged as promising tools in the diagnosis of early bile duct cancer. Recently, digitized image analysis (DIA) and fluorescence in situ hybridization (FISH) offer promise to evaluate bile duct cancers in terms of cellular aneuploidy and chromosomal aberrations ${ }^{[1,46-48]}$. Recent reports have demonstrated that their sensitivities are superior and specificities are similar to standard cytology for the diagnosis of bile duct cancer ${ }^{[4-48]}$. Positron emission tomography (PET) imaging is another emerging diagnostic technique for the detection of bile duct cancer. PET scanning can detect nodular bile duct cancer as small as 1 $\mathrm{cm}$ but is less helpful for infiltrating tumors ${ }^{[49]}$. PET can be utilized to ascertain an malignancy by finding hot uptake at the suspected site, when histological sampling is difficult ${ }^{[27]}$. As this technique becomes more widely available, additional information on its use for the diagnosis of early bile duct cancer will be forthcoming.

\section{A PROPOSED ALGORITHM FOR DETECTING EARLY BILE DUCT CANCER IN CLINICAL PRACTICE}

There are largely two clinical settings that early bile duct cancer can be diagnosed prospectively. The first is detection of bile duct dilatation on imaging such as an abdominal US ${ }^{[2,3,27]}$. This could be in asymptomatic patients undergoing health screening, in workup of vague or nonspecific abdominal discomfort or incidentally detected abnormalities in the enzyme of bile duct origin (such as alkaline phosphatase or gamma glutamyltransferase). The next step in assessing dilated bile ducts found on US includes biliary dynamic CT and/or MRC (Figure 3). Focal biliary stricture or a suspicious intraductal polypoid mass with proximal ductal dilatation detected on these tests raises a high suspicion of bile duct cancer. If the suspected lesion is extrahepatic in location, histopathologic sampling is possible without difficulty by brush cytology and/or biopsy through ERCP. If available, peroral cholangioscopy can also be attempted. EUS with fine needle aspiration is also emerging as a promising tool in the differential diagnosis of extrahepatic bile duct wall thickening as well ${ }^{[45]}$. If the suspected lesion is intrahepatic in location, PET can be utilized to ascertain its malignant nature by finding hot uptake at the suspected site ${ }^{[27]}$. For PET-negative intrahepatic lesions, it is our practice to confirm the nature of the lesion by PTCS with biopsy. Although some do not recommend percutaneous biopsy 


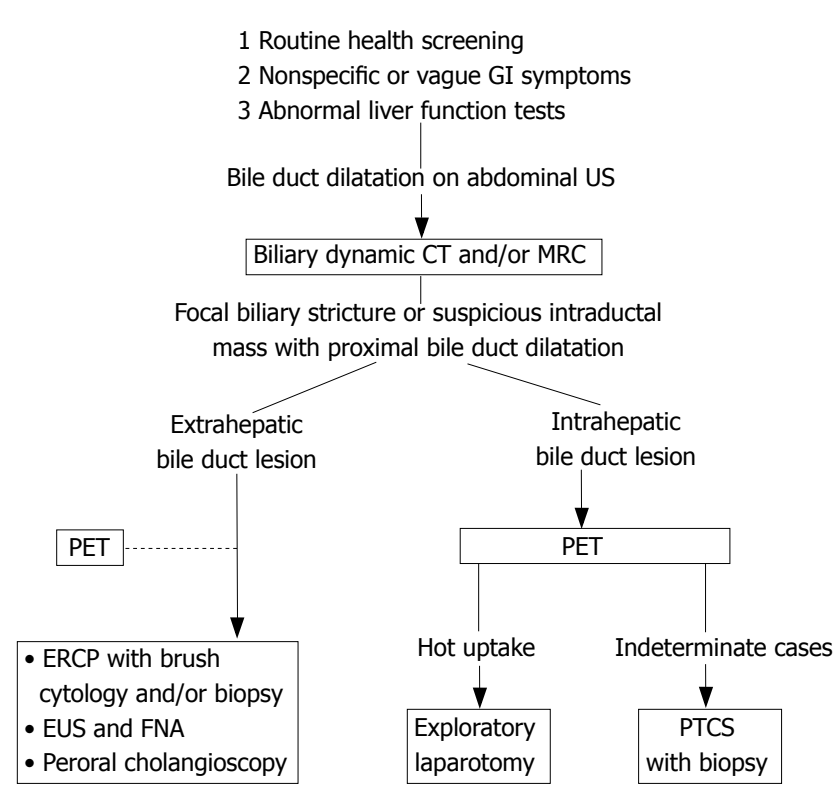

Figure 3 Proposed algorithm for detecting an early bile duct cancer. GI: gastrointestinal; US: ultrasound; CT: computed tomography; MRC: magnetic resonance cholangiography; PET: positron emission tomography; ERCP: endoscopic retrograde cholangiopancreatography; EUS: endoscopic ultrasound; FNA: fine needle aspiration; PTCS: percutaneous transhepatic cholangioscopy.

for potentially resectable bile duct cancer due to the risk of tumor seeding ${ }^{[50]}$, confirming malignancy in equivocal cases greatly increases both the compliance of patients with no current symptoms and the confidence of the physician, planning a major operation such as hepatic resection.

The second clinical pathway that early bile duct cancer can be diagnosed is during the follow up of patients with known risk factors for bile duct cancer. These patients undergo periodic liver function tests, serum tumor markers tests, and abdominal US as a surveillance. Detection of a progressive increase of bile duct origin enzymes and tumor markers or progression of bile duct dilatation suggests change in their clinical status and warrants further evaluation including biliary CT or MRC. Finding of a newly appeared or aggravated ductal stricture and/or a mass suggests development of a bile duct cancer, and the subsequent workup follows the clinical pathway previously mentioned. One note for this latter group is that more cautious interpretation of PET results is needed as a false positive result for their inflammatory conditions such as cholangitis or abscess is possible in this group.

\section{PROGNOSIS}

Over half of patients with advanced bile duct cancer present with unresectable malignancies, and the 5-year survival rate of these patients is approximately $15 \%-35 \%$ even after curative resections ${ }^{[1,2,13,25,31,51,52]}$. Early bile duct cancer patients should have markedly better surgical outcomes than advanced bile duct cancer patients. In this regard, the reported 5-year survival rate for patients with early bile duct cancer has been promising ${ }^{[4,7,15]}$. Mizumoto et $a l^{[7]}$ reported a 5 year survival rate for early bile duct cancer of $100 \%$, and Kurosaki et a ${ }^{[9]}$ reported a 5-year survival rate for seven patients with p'T1 bile duct cancer of $86 \%$. Recently, we also demonstrated a 5 -year survival rate for early bile duct cancer patients of $80 \%{ }^{[4]}$. Therefore, we believe that detection of early bile duct cancer may provide the opportunity for better prognosis in bile duct cancer.

In terms of disease recurrence, Tsunoda et at found that $1(13 \%)$ of 8 early bile duct cancer patients died due to recurrence, and Yamaguchi ${ }^{[6]}$ found that $1(14 \%)$ of 7 early bile duct cancer patients died from liver metastasis. In contrast, Mizumoto et al ${ }^{[7]}$ reported no recurrence in early bile duct cancer patients for periods between 3 years and 8 years after surgery. In our series, disease recurrence developed in $8(13 \%)$ of 61 patients ${ }^{[4]}$. Not infrequent disease recurrences in patients with early bile duct cancer may be explained by the fact that intraductal-growing types or papillary carcinomas may remain undetected by conventional imaging studies due to their tendency to spread superficially along the mucosa. Therefore, accurate pre-operative evaluation of disease extent should be emphasized in early bile duct cancer patients.

Major prognostic determinant may be the detection of early cancer rather than histological tumor types. Papillary carcinomas were believed to have a more favorable outcome than other histological types in bile duct cancers ${ }^{[39,53]}$; however, longer survival was linked with early detection regardless of gross or histological types in patients with early bile duct cancer ${ }^{[4]}$. In accordance with our notion, Kurosaki et al ${ }^{[9]}$ also found that patients with pT1 papillary carcinoma showed relatively prolonged survival, whereas patients with p'2 or pT3 papillary carcinoma did not show such a long survival.

\section{CONCLUSION}

As the prognosis of bile duct cancer remains disappointing in general and no breakthrough has been achieved recently, it is encouraging to see a dramatic improvement in the prognosis of a subset of bile duct cancer identified as early bile duct cancer. Clinicians may be successful in identifying early bile duct cancer cases if they have a high index of suspicion and knowledge regarding this disease entity. The answer for the better prognosis in bile duct cancer may be provided by introduction of the concept of early bile duct cancer.

\section{REFERENCES}

1 Lazaridis KN, Gores GJ. Cholangiocarcinoma. Gastroenterology 2005; 128: 1655-1667

2 Olnes MJ, Erlich R. A review and update on cholangiocarcinoma. Oncology 2004; 66: 167-179

3 Lim JH. Cholangiocarcinoma: recent advances in imaging and intervention. Abdom Imaging 2004; 29: 538-539

4 Cha JM, Kim MH, Lee SK, Seo DW, Lee SS, Lee JH, Lee SG, Jang SJ. Clinicopathological review of 61 patients with early bile duct cancer. Clin Oncol (R Coll Radiol) 2006; 18: 669-677

5 Tsunoda T, Eto T, Koga M, Tomioka T, Motoshima K, Yamaguchi T, Izawa K, Tsuchiya R. Early carcinoma of the extrahepatic bile duct. Jpn J Surg 1989; 19: 691-698

6 Yamaguchi K. Early bile duct carcinoma. Aust N Z J Surg 1992; 62: 525-529

7 Mizumoto R, Ogura Y, Kusuda T. Definition and diagnosis of early cancer of the biliary tract. Hepatogastroenterology 1993; 40: 


\section{9-77}

8 Bhuiya MR, Nimura Y, Kamiya J, Kondo S, Nagino M, Hayakawa N. Clinicopathologic factors influencing survival of patients with bile duct carcinoma: multivariate statistical analysis. World J Surg 1993; 17: 653-657

9 Kurosaki I, Tsukada K, Watanabe H, Hatakeyama K. Prognostic determinants in extrahepatic bile duct cancer. Hepatogastroenterology 1998; 45: 905-909

10 Tamada K, Tomiyama T, Wada S, Ohashi A, Satoh Y, Ido K, Sugano K. Cholangiographic findings of early-stage extrahepatic bile duct carcinoma. J Gastroenterol 2001; 36: 837-841

11 Lim JH, Jang KT, Choi D, Lee WJ, Lim HK. Early bile duct carcinoma: comparison of imaging features with pathologic findings. Radiology 2006; 238: 542-548

12 Okuda K, Nakanuma Y, Miyazaki M. Cholangiocarcinoma: recent progress. Part 1: epidemiology and etiology. J Gastroenterol Hepatol 2002; 17: 1049-1055

13 Nakeeb A, Pitt HA, Sohn TA, Coleman J, Abrams RA, Piantadosi S, Hruban RH, Lillemoe KD, Yeo CJ, Cameron JL. Cholangiocarcinoma. A spectrum of intrahepatic, perihilar, and distal tumors. Ann Surg 1996; 224: 463-473; discussion 473-475

14 Crawford JM. Development of the intrahepatic biliary tree. Semin Liver Dis 2002; 22: 213-226

15 Nakanuma Y, Hoso M, Sanzen T, Sasaki M. Microstructure and development of the normal and pathologic biliary tract in humans, including blood supply. Microsc Res Tech 1997; 38: $552-570$

16 Hong SM, Kang GH, Lee HY, Ro JY. Smooth muscle distribution in the extrahepatic bile duct: histologic and immunohistochemical studies of 122 cases. Am J Surg Pathol 2000; 24: 660-667

17 Hong SM, Presley AE, Stelow EB, Frierson HF, Moskaluk CA. Reconsideration of the histologic definitions used in the pathologic staging of extrahepatic bile duct carcinoma. Am J Surg Pathol 2006; 30: 744-749

18 Demetris AJ, Lunz JG, Specht S, Nozaki I. Biliary wound healing, ductular reactions, and IL-6/gp130 signaling in the development of liver disease. World J Gastroenterol 2006; 12: 3512-3522

19 Hidaka E, Yanagisawa A, Makoto S, Takano K, Kato H. The opinions from the standpoint of pathology concerning "General Rules for surgical and pathological studies on cancer of the biliary tract, the 4th edition." Kan Tan Sui 2000; 41: 543-550 (In Japanese)

20 Huang JL, Biehl TR, Lee FT, Zimmer PW, Ryan JA. Outcomes after resection of cholangiocellular carcinoma. Am J Surg 2004; 187: 612-617

21 Fleming ID, Cooper JS, Hensen DE, Hutter RVP, Kennedy BJ, Murphy GP, O'Sullivan B, Sobin LH, Yarbro JW. AJCC cancer staging manual, 5th ed. Philadelphia: Lippincott-Raven, 1998; 97-114

22 Greene FL, Page DL, Fleming ID, Fritz A, Balch CM, Haller DG, Morrow M. AJCC cancer staging manual, 6th ed. New York: Springer-Verlag, 2002; 131-150

23 Hong SM, Kim MJ, Pi DY, Jo D, Cho HJ, Yu E, Ro JY. Analysis of extrahepatic bile duct carcinomas according to the New American Joint Committee on Cancer staging system focused on tumor classification problems in 222 patients. Cancer 2005; 104: $802-810$

24 Ahn YO, Park BJ, Yoo KY, Lee HS, Kim CY, Shigematsu T. Incidence estimation of primary liver cancer among Koreans. J Korean Cancer Assoc 1989; 21: 241-248 (In Korean)

25 de Groen PC, Gores GJ, LaRusso NF, Gunderson LL, Nagorney DM. Biliary tract cancers. N Engl J Med 1999; 341: 1368-1378

26 Kim MH, Yasuda K. Percutaneous transhepatic cholangioscopic examination: a necessity for the biliary endoscopist. Gastrointest Endosc 2001; 53: 695-697

27 Khan SA, Thomas HC, Davidson BR, Taylor-Robinson SD. Cholangiocarcinoma. Lancet 2005; 366: 1303-1314

28 Rosen CB, Nagorney DM, Wiesner RH, Coffey RJ, LaRusso
NF. Cholangiocarcinoma complicating primary sclerosing cholangitis. Ann Surg 1991; 213: 21-25

29 Kim JY, Kim MH, Kim SD, Lee JH, Ahn SK, Park DH, Song MH, Lee SS, Seo DW, Lee SK, Min YI. 28 cases of primary sclerosing cholangitis. Korean J Med 2004; 66: 127-134 (In Korean)

30 Takikawa $\mathbf{H}$, Manabe T. Primary sclerosing cholangitis in Japan--analysis of 192 cases. J Gastroenterol 1997; 32: 134-137

31 Lee SS, Kim MH, Lee SK, Jang SJ, Song MH, Kim KP, Kim HJ, Seo DW, Song DE, Yu E, Lee SG, Min YI. Clinicopathologic review of 58 patients with biliary papillomatosis. Cancer 2004; 100: 783-793

32 Kim JE, Lee KT, Lee JK, Paik SW, Rhee JC, Choi KW. Clinical usefulness of carbohydrate antigen $19-9$ as a screening test for pancreatic cancer in an asymptomatic population. $J$ Gastroenterol Hepatol 2004; 19: 182-186

33 Nichols JC, Gores GJ, LaRusso NF, Wiesner RH, Nagorney DM, Ritts RE. Diagnostic role of serum CA 19-9 for cholangiocarcinoma in patients with primary sclerosing cholangitis. Mayo Clin Proc 1993; 68: 874-879

34 Liver Cancer Study Group of Japan. The general rules for the clinical and pathological study of primary liver cancer (In Japanese). 4th ed. Tokyo: Kanehara, 2000; 19

35 Rosai T. Rosai and Ackerman's surgical pathology. 9th ed. St Louis:Mosby, 2004; 1049-1050

36 Kozuka S, Tsubone M, Hachisuka K. Evolution of carcinoma in the extrahepatic bile ducts. Cancer 1984; 54: 65-72

37 Stains S, Parekh D, Selby R. Tumors of the gallbladder and the biliary tract. In: Kaplowitz N. Liver and biliary disease. 2nd ed. Baltimore: Williams \& Wilkins, 1996; 730-734

38 Takehara Y. Preoperative assessment of extrahepatic cholangiocarcinoma with imaging. Abdom Imaging 2004; 29: 572-580

39 Zandrino F, Curone P, Benzi L, Ferretti ML, Musante F. MR versus multislice $\mathrm{CT}$ cholangiography in evaluating patients with obstruction of the biliary tract. Abdom Imaging 2005; 30: 77-85

40 Tischendorf JJ, Krüger M, Trautwein C, Duckstein N, Schneider A, Manns MP, Meier PN. Cholangioscopic characterization of dominant bile duct stenoses in patients with primary sclerosing cholangitis. Endoscopy 2006; 38: 665-669

41 Hadjis NS, Collier NA, Blumgart LH. Malignant masquerade at the hilum of the liver. Br J Surg 1985; 72: 659-661

42 Albert MB, Steinberg WM, Henry JP. Elevated serum levels of tumor marker CA19-9 in acute cholangitis. Dig Dis Sci 1988; 33: $1223-1225$

43 Tsuyuguchi T, Fukuda Y, Saisho H. Peroral cholangioscopy for the diagnosis and treatment of biliary diseases. J Hepatobiliary Pancreat Surg 2006; 13: 94-99

44 O'Toole D, Palazzo L. Choledocholithiasis--a practical approach from the endosonographer. Endoscopy 2006; 38 Suppl 1: S23-S29

45 DeWitt J, Misra VL, Leblanc JK, McHenry L, Sherman S. EUSguided FNA of proximal biliary strictures after negative ERCP brush cytology results. Gastrointest Endosc 2006; 64: 325-333

46 Gores GJ. Early detection and treatment of cholangiocarcinoma. Liver Transpl 2000; 6: S30-S34

47 Kipp BR, Stadheim LM, Halling SA, Pochron NL, Harmsen S, Nagorney DM, Sebo TJ, Therneau TM, Gores GJ, de Groen PC, Baron TH, Levy MJ, Halling KC, Roberts LR. A comparison of routine cytology and fluorescence in situ hybridization for the detection of malignant bile duct strictures. Am J Gastroenterol 2004; 99: 1675-1681

48 Rumalla A, Baron TH, Leontovich O, Burgart LJ, Yacavone RF, Therneau TM, de Groen PC, Sebo TJ. Improved diagnostic yield of endoscopic biliary brush cytology by digital image analysis. Mayo Clin Proc 2001; 76: 29-33

49 Anderson CD, Rice MH, Pinson CW, Chapman WC, Chari RS, Delbeke D. Fluorodeoxyglucose PET imaging in the evaluation of gallbladder carcinoma and cholangiocarcinoma. J Gastrointest Surg 2004; 8: 90-97

50 Khan SA, Davidson BR, Goldin R, Pereira SP, Rosenberg WM, 
Taylor-Robinson SD, Thillainayagam AV, Thomas HC, Thursz MR, Wasan H. Guidelines for the diagnosis and treatment of cholangiocarcinoma: consensus document. Gut 2002; 51 Suppl 6: VI1-VI9

51 Nakeeb A, Tran KQ, Black MJ, Erickson BA, Ritch PS, Quebbeman EJ, Wilson SD, Demeure MJ, Rilling WS, Dua KS, Pitt HA. Improved survival in resected biliary malignancies.
Surgery 2002; 132: 555-563; discission 563-564

52 Jan YY, Jeng LB, Hwang TL, Wang CS, Chen MF, Chen TJ. Factors influencing survival after hepatectomy for peripheral cholangiocarcinoma. Hepatogastroenterology 1996; 43: 614-619

53 Ouchi K, Matsuno S, Sato T. Long-term survival in carcinoma of the biliary tract. Analysis of prognostic factors in 146 resections. Arch Surg 1989; 124: 248-252

S- Editor Zhu LH L- Editor Zhu LH E- Editor Chen GJ 